\title{
Normas de intervenção humanitária: Responsabilidade ao Proteger (RwP) como contestação do Sul Global
}

\author{
Norm s of humanitarian intervention: Responsibility while Protecting (RwP) a s a contestation of the Global \\ South
}

DOI: https://doi.org/10.22456/2178-8839.113903

Ana Clara Figueira Guimarães Programa de Pós-graduação em Relações Internacionais San Tiago Dantas, São Paulo, Brasil anaclarafigueiraguimaraes@gmail.com $\mathbf{O}$

Alexandre Fuccille Universidade Estadual Paulista “Júlio de Mesquita Filho”, São Paulo, Brasil alexandre.fuccille@unesp.br

\section{Resumo}

As normas de intervenção humanitária adquiriram notoriedade após acontecimentos históricos de atrocidades em massa contra civis. Nesta conjuntur a surgiu, em 2001, o princípio da Responsabilidade de Proteger (R2P). Seu ponto de inflexão se deu por meio da Resolução n¹973 no ano de 2011 - emanada pelo Conselho de Segurança da ONU-que redundou na intervenção na Líbia. Em resposta aos excessos e falhas ocorridos durante a implementação da resolução, o Brasil, numa iniciativa como empreendedor normativo, propôs a Responsabilidade ao Proteger (RwP). Neste sentido, visa-se identificar como se insere esta proposta normativa da RwP no vasto panorama da evolução das normas de intervenção humanitária, isto é, no meio normativo internacional. Aborda-se a RwP como exemplo de uma tentativa normativa imersa no escopo internacional das regras sobre o uso da força, ressaltando se o seu caráter propositivo, decorrente da falta de esforço do Brasil em consolidar o conceito no âmbito das Nações Unidas. Assim, a partir de uma análise do conteúdo dos discursos envolvidos no contexto de sua criação, e considerando o grande debate sobre normas novas ou modificadas pelos países da periferia mundial, constatou-se que a RwP foi uma iniciativa normativa contestativa aplicacional do Sul Global complementar à atuação humanitária.

Palavras-chave: Normas de Intervenção Humanitária; Responsabilidade ao Proteger (RwP); Responsabilidade de Proteger (R2P);

\begin{abstract}
The norms of humanitarian intervention have gained notoriety after historical events of mass atrocities against civilians. In this context, the principle of Responsibility to Protect (R2P) emerged in 2001. Its tipping point was given through Resolution No. 1973 in 2011 - issued by the UN Security Council which resulted in the intervention in Libya. In response to the excesses and failures that occurred during the implementation of the resolution, Brazil, in an initiative as a normative entrepreneur, proposed Responsibility while Protecting (RwP). In this sense, the present work aims to identify how this RwP normative proposal fits into the vast panorama of the evolution of the norms of humanitarian intervention, that is, in the international political and normative environment. RwP is an example of a normative attempt immersed in the international scope of the rules on the use of force, emphasizing its propositional character. Hence, from an analysis of the content of the speeches involved in the context of its creation, and considering the great debate about new or modified standards by countries in the world periphery, it was found that RwP was a contestative normative initiative of the Global South, complementary to humanitarian action.
\end{abstract}

Keywords: Norms of humanitarian intervention; Responsibility while Protecting (RwP); Responsibility to Protect (R2P); 


\section{Introdução}

A grande discussão sobre as intervenções humanitárias, fundamentada na teoria da guerra justa, foi concebida a partir do século XIX e envolve a matéria primordial do emprego da força. As intervenções humanitárias podem ser definidas como ações militares ou não, com o objetivo de prevenir ou acabar com violações dos Direitos Humanos (DH), mesmo na ausência do consentimento do Estado receptor (BIGATÃO, 2009, p. 88). O debate central se encontra no “quando a força é legítima e que tipos de objetivos ela pode alcançar” (FINNEMORE, 2003, p.1, tradução nossa).

A discussão polariza-se entre os defensores da intervenção humanitária, baseada na noção de que os Estados teriam o direito de intervir militarmente em outros Estados, mesmo sem o consentimento destes, para a defesa dos indivíduos, e os apoiadores das prerrogativas tradicionais da soberania estatal, contrários à ingerência em assuntos internos de outros Estados (EVANS, 2008, p. 285). Esta polarização entre o direito de intervenção humanitária e a soberania é caracterizada pelo contraste entre os países desenvolvidos e os em desenvolvimento (BIERRENBACH, 2011, p. 14), visto que os novos Estados recém-criados, assim como os países do Sul Global, tendem a defender a soberania recentemente conquistada, e os países do Norte irão defender a flexibilização da soberania, isto é, a intervenção por motivos humanitários (EVANS, 2008,p. 285).

As questões das intervenções humanitárias são polêmicas, e sua discussão foi aprofundada e influenciada devido à acontecimentos históricos de atrocidades em massa ocorridos na década de 1990, redundando em um aumento expressivo das operações de paz durante esse período (DIGOLIN, 2018,p. 96). Esses casos históricos de crises humanitárias tiveram impetuosas repercussões sobre o debate ao trazerem questionamentos sobre a seletividade da vontade internacional e a legitimidade das intervenções em Estados soberanos (ICISS, 2001,p.1). Deste modo, podemos tomá -los como responsáveis pela pressão da sociedade civil quanto às reações às atrocidades em massa.

No contexto pós-Guerra Fria, numa nova ordem internacional assente no sistema de segurança coletiva e na evolução do Direito Internacional (DI) e dos DH, resultando no nomeado Direito da Humanidade, criou-se uma dimensão no contexto internacional em que há a oportunidade e a capacidade de ação comum em relação às questões de proteção humana, refletindo no crescente reconhecimento mundial de que a segurança humana, incluindo a dignidade humana, os $\mathrm{DH}$ e as liberdades individuais, devem representar juntos parte dos propósitos centrais das políticas estatais e das instituições internacionais (ICISS, 2001, p. 6).

O debate sobre as intervenções humanitárias reúne, portanto, o conflito entre o princípio da não intervenção, a soberania e os DH. De modo a conciliar essas questões, assim como as diferentes vertentes e entendimentos quanto ao uso da força para a proteção de civis em casos extremos, a International Commission on Intervention and State Sovereignty (ICISS) ${ }^{1}$ elaborou o conceito da "Responsabilidade de Proteger" (R2P) em 2001, que envolve ação preventiva efetiva e tempestiva a quatro restritos crimes e violações - genocídio, crimes de guerra, limpeza étnica e crimes contra a humanidade (UN GENERAL ASSEMBLY, 2005, \$138).

Esse conceito se consolidou como princípio do DI, em 2005, na Cúpula Mundial das Nações Unidas, e teve seu ponto de inflexãona Resoluçãon 01973 no ano de 2011 - emanada pelo Conselho de Segurança das Nações Unidas (CSNU) ${ }^{2}$ que redundou na intervenção na guerra civil da Líbia. O CSNU, nessa resolução, utilizou o princípio da R2P para condenar o governo líbio por permitir graves violações do DH e ataques equivalentes a crimes contra a humanidade.

A operação militar na Líbia, durante o que ocidentalmente se convencionou chamar "Primavera Árabe”, foi o principal exemplo da utilização do princípio da R2P porque marcou a primeira vez que o CSNU autorizou o uso da força militar para fins de proteção de pessoas sem o consentimento do país em que se estavaintervindo (BELLAMY; WILLIAMS,

\footnotetext{
Essa comissão internacional independente foi um painel formado por especialistas internacionais, lançado em 14 de setembro de 2000 (ICISS, 2001 , p. 81), que conduziu uma série de consultas a governos, ONGs, organizações intergovernamentais, universidades, representantes da sociedade civil e think tanks. Como resultado, elaborou-se um relatório intitulado "A Responsabilidade de Proteger", que foi aprovado por unanimidade por seus doze comissários, em setembro de 2001.

2 Órgão deliberativo e tomador de decisões da Organização das Nações Unidas (ONU) sobre a manutenção da paz e da segurança internacional.
} 
2011, p. 825). Não obstante, críticas e contestações da comunidade internacional seguiram-se após a aplicação da R2P em casos como o da Líbia e da Costa do Marfim. ${ }^{3}$ Apesar da R2P ter se consolidado como princípio do DI em 2005, há um imenso debate sobre sua implementação, ou seja, a aplicação do princípio e as consequências morais e práticas da intervenção (ZIEGLER, 2016, p.3).

Em resposta aos excessos e falhas ocorridos durante a implementação da resolução, o Brasil teve uma posição ativa e construtiva como empreendedor normativo, ao propor a Responsabilidade ao Proteger (RwP). Este conceito foi citado pelo Brasil originalmente em 21 de setembro de 2011, por ocasião da abertura da Assembleia Geral das Nações Unidas $(\mathrm{AGNU})^{4}$, oportunidade em que este evento anual, pela primeira vez na história foi aberto por uma mulher, a presidenta Dilma Rousseff, e propunha a adoção de um conjunto de princípios e parâmetros para a regulação das missões humanitárias, destacadamente para a implementação da R2P (BRAZIL, 2011, p. 5; PERMANENT REPRESENTATIVE OF BRAZIL TO THE UNITED NATIONS, 2011). ${ }^{5}$

A presente pesquisa relatada e sintetizada neste artigo considera o grande debate sobre normas novas ou modificadas pelos países da periferia mundial e visa identificar onde e como se insere essa proposta normativa da RwP no vasto panorama da evolução das normas de intervenção humanitária, isto é, no meio normativo internacional. Em relação ao modo de inserção da RwP no quadro das normas de intervenção humanitária, foram elencadas algumas possibilidades com base na literatura estudada: inovação, complementação e contestação.

Considerando a Organização das Nações Unidas (ONU) como ambiente dos debates, e examinando o comportamento e o discurso sobre a RwP, procuramos responder se a RwP foi um exemplo de contestação, se buscou complementar ou inovar o escopo das normas, e/ou ações de intervenção humanitária. No entanto, sem olvidar o aspecto do contexto regional e da particularização do ator como integrante do Sul Global. A nossa hipótese é que a RwP foi uma forma contestativa aplicacional complementar à atuação humanitária, isto é, buscou contestar e adicionar valor à dimensão prática, ou melhor, da aplicação da norma, e não ao vasto quadro formal das normas em si, isto é, quanto ao conteúdo substantivo da norma da R2P, utilizando, assim, a tipologia de contestação da Deitelhoff e Zimmermann (2018).

Com o intuito de interpretarmos o processo de construção das normas internacionais, na pesquisa realizada, procuramos evidenciar a dinâmica construtivista das ideias, interesses, normas e comportamento. Posteriormente, evidenciamos também os diferentes modelos de análise sobre difusão das normas globais, já que apreciamos a RwP como um conceito com pretensão de norma global, para entender a dinâmica de evolução das normas de intervenção humanitária, processada pela ocorrência de contestação aos consensos. Tendo em mente este embasamento teórico, diferenciamos os tipos de contestação usando a teoria da contestação, para finalmente localizar e atribuir o papel da RwP na estrutura dinâmica normativa internacional.

Cabe "ressaltar que o Sul Global elabora poucas propostas de normas que sejam construtivas no âmbito global" (STUENKEL, 2013, p. 59, tradução nossa), o que faz com que a iniciativa brasileira seja considerada um elemento importante no processo da multipolarização e de evolução das normas globais.

Vale destacar que existe um questionamento quantoà categorização da RwP como norma, porém, para fins desta análise, consideramos a RwP como uma proposta normativa não concretizada como norma, no entanto, impactada pela

\footnotetext{
Após a aplicação do princípio da R2P é possível identificar uma "desconexão abissal entre o diálogo político em torno da R2P e a realidade no terreno" (KELLY,2013, p. 52). Neste sentido, a comunidade internacional, na primeira implementação do conceito, propôs soluções de cer ta forma desconexas da realidade, ao ter como foco somente o objetivo central (proteção dos civis), e ignorar a observação da realidade (atores envolvidos e seus interesses) e as análises de causas e consequências.

4 Principal órgão da ONU composto por todos os países membros que se reúnem para discutir questões que impactam a vida de todos os habitantes do planeta.

5 A diplomata Maria Luiza Ribeiro Viotti, em 09 de novembro de 2011, proferiu uma declaração em nome do Embaixador Antônio Patriota, Ministro das Relações Exteriores do Brasil, durante o 12th Open Debate of the Security Council on Protection of Civilians in Armed Conflicts, no qual anunciou que o Brasil divulgaria em breve um documento conceitual sobre a ideia da RwP mencionada pela presidenta em seu discurso (MRE, 2011). Em seguida, a Representante Permanente do Brasil junto à ONU enviou uma carta ao Secretário-Geral com a nota conceitual anexada e intitulada "Responsabilidade ao Proteger: elementos para o desenvolvimento e promoção de um conceito", e ainda solicitou sua publicação como documento da AGNU e do CSNU com a intenção de chegar ao conhecimento de todos os países membros (PERMANENT REPRESENTATIVE OF BRAZIL TO THE UNITED NATIONS, 2011).
} 
dinâmica das normas, ressaltando a necessidade de recorrer à teoria de difusão de normas na análise da iniciativa normativa (ACHARYA, 2004; FLORINI, 1996; FINNEMORE; SIKKINK, 1998; WIENER, 2007a). Porém, esse debate teórico não será explorado aqui devido ao formato reduzido desta exposição.

Segundo Antje Wiener (2007c), "as intervenções discursivas são, portanto, consideradas o fator central para avaliar empiricamente o significado das normas", logo utilizamos a análise de conteúdo como metodologia. Portanto, fizemos uso de uma análise do conteúdo dos discursos envolvidos no contexto de criação do conceito para identificar se a RwP foi, ou não, uma forma de contestação no tocante ao escopo das normas de intervenção humanitária em geral, ou particularmente à R2P, ou seja, a norma elaborada pelos países ocidentais.

Salientando assim a importância da diferenciação entre o conteúdo da norma e a implementação, desta divisão primeiramente enfatizada pelo Brasil de acordo com Kenkel e Rosa (2015). Esta separação também é feita pelo Amitav Acharya, quanto às práticas de localização e subsidiariedade, e é feita por Deitelhoff e Zimmermann (2018), quanto aos tipos de contestação: de validade e de aplicação, por isto usamos estas duas perspectivas para a análise em questão. À vista disto, se a RwP foi uma proposta normativa que se encontra como uma contestação à norma existente da R2P, indaga-se em qual desses tipos de contestação a RwP se insere.

Devido à limitação de espaço do artigo, iremos somente apresentar resumidamente as ideias e debates centrais da pesquisa em questão. Dessa forma, estrutura-se o artigo em cinco seções. Primeiramente, apresentaremos a R2P destacando o contexto e as fontes normativas estruturantes da norma, sua consolidação em 2005 e implementação em 2011 a fim de solucionar o conflito na Líbia, e ainda os principais aspectos enfatizados no debate pós -intervenção no âmbito do CSNU. Em seguida, abordaremos a RwP examinando o contexto internacional e institucional do surgimento da nota conceitual e as fontes normativas, com base no arcabouço normativo da R2P. Ademais, relataremos a reação internacional sobre a iniciativa normativa e os principais questionamentos em torno desta. Por último, salientaremos a análise do modo de inserção dessa iniciativa e as considerações finais.

\section{Responsabilidade de Proteger (R2P)}

O princípio da R2P se encontra no âmbito do amplo contexto normativo das intervenções humanitárias. $\mathrm{O}$ relatório chamado "Responsabilidade de Proteger”, apresentou dois princípios -base para o conceito: a "soberania estatal implica responsabilidade, e a responsabilidade primária para a proteção do seu povo é do próprio Es tado” (ICISS, 2001, p. XI, tradução nossa), uma vez que a autoridade nacional tem a melhor disposição para evitar, entender e lidar com problemas relacionados à proteção do seu povo. Porém, em situações

[...] onde uma população sofre danos graves, como resultado de uma guerra interna, insurgência, repressão ou a falência do Estado, e o Estado em questão é incapaz de deter esses danos ou evitá -los, o princípio da não-intervenção gera a responsabilidade internacional de proteger (ICISS, 2001, p. XI, tradução nossa). ${ }^{6}$

Nesse sentido, o ICISS modificou o estigma coercitivo associado à ideia de "intervenção humanitária” ao estabelecer que o foco deste conceito não está na noção do “direito" de intervenção, e sim na responsabilidade de todos os Estados de "proteger" os indivíduos (EVANS, 2008, p. 285; ICISS, 2001, p. 11), isto é, no dever moral (ANNAN, 2000, p. 34). ${ }^{7}$ Além do mais, segundo Acharya, "o papel da ICISS no desenvolvimento da R2P não foi apenas "reformular" e, assim,

\footnotetext{
${ }^{6}$ É importante evidenciar que o conceito da R2P foi concebido pela primeira vez por Francis Deng, e desenvolvido depois pela ICISS (POWERS, LINDBLAD, et al., 2015, p. 4, tradução nossa).

"A intervenção humanitária é uma questão delicada, cheia de dificuldades políticas, e não suscetível a respostas fáceis. Mas certamente nenhum princípio jurídico - nem mesmo a soberania - pode jamais proteger crimes contra a humanidade. Quando tais crimes ocorrem e as tentativas pacíficas de detê-los são esgotadas, o Conselho de Segurança tem o dever moral de agir em nome da comunidade internacional. O fato de não poder mos proteger as pessoas em todos os lugares não é motivo para não fazer nada quando podemos. A intervenção armada deve sempre permanecer como a opção de último recurso, mas, diante do assassinato em massa, é uma opção que não pode ser abandonada” (ANNAN, 2000, p.34, tradução nossa).
} 
"suavizar" a ideia de intervenção humanitária do "direito de intervir" à "responsabilidade de proteger", porque essa se tornou controversa demais para os países em desenvolvimento." (ACHARYA, 2015, p. 61, traduçãonossa).

De acordo com o autor, a R2P tem em sua origem diversas fontes e contextos, dentre os quais pode-se destacar: o relatório da ICISS, a ideia de intervenção humanitária, a concepção de soberania responsável delineada num contexto africano, os debates sobre os DH e a tradição da guerra justa (ACHARYA, 2015, p. 76). Logo, a R2P não é somente um novo código para intervenção humanitária, mas sim um conceito mais positivo e afirmativo da soberania como responsabilidade (BAN KI-MOON, 2008).

Em 2005, na Cúpula Mundial da ONU, os Estados concordaram, por unanimidade, com esse desenvolvimento conceitual, e adotaram o conceito de "Responsabilidade de Proteger". O contexto normativo sobre as questões humanitárias de intervenção sofreu uma mudança, principalmente quanto aos entendimentos normativos sobre quais seres humanos devem ser protegidos militarmente, e a concepção da forma de implementação de como essa proteção deveria ocorrer (FINNEMORE, 1996a, p. 2). Essa mudança no contexto social se refletiu na consolidação da norma da R2P e no comportamento dos Estados, ao ser possível identificar o consenso quanto ao interesse em proteger não-cristãos, nãoeuropeus e à sua efetivação de forma multilateral sob estratégias coletivas, através da ONU (FINNEMORE, 1996 a).

A R2P atingiu o seu auge quando foi usada como base para decisões do CSNU em 2011, na Resolução n 1973,

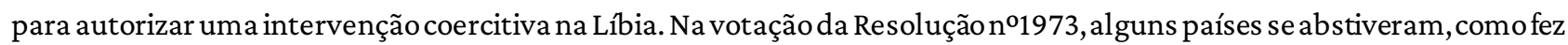
o Brasil, o que não quer dizer que o país apoiava ou negligenciava as atrocidades cometidas pelo Gaddafi (ONU, 2011, p. 6).

As opiniões sobre o caso da Líbia na comunidade internacional em geral divergem consideravelmente: ao passo que alguns o defendem na qualidade de melhor execução do princípio da R2P, outros o caracterizam como um desastre humanitário (ZIEGLER, 2016, p. 2; STUENKEL, 2013, p. 60). Na verdade,identifica-se que o Ocidente considerou um grande sucesso ${ }^{8}$, enquanto o Sul Globalviu como um retrocesso (STUENKEL, 2013, p. 60). Entre as principais críticas à intervenção na Líbia, sobressaem-se duas: a parcialidade da OTAN e a mudança de regime (CARPIO, 2014, p.103).

A partir dos relatos dos países do BRICS durante a votação da Resolução no1973 é possível identificar que, de modo geral, estes apoiaram parcialmente a resolução no entendimento de que era necessária uma ação internacional drástica (ADAMS, 2012, p. 2), mas eles são considerados relutantes ${ }^{9}$ ao avanço da aplicação da norma ${ }^{10}$, uma vez que esta reflete a ordem ocidental liberal estabelecida pela hegemonia americana pós -Guerra Fria (ZIEGLER, 2016, p. 6). Dessa maneira, a relutância das potências emergentes se encontra além da resistência à forma de implementação, já que expressa a repulsa ao processo hierárquico e de relações estáticas de poder pelo qual se desenvolve ess a aplicação (KENKEL; DESTRADI, 2019). Desta forma, cabe ressaltar que a R2P representa uma disputa normativa entre o Norte e o Sul Global. Sendo assim, a intenção de criar o princípio, na tentativa de estabelecer uma "ponte" entre o Norte e o Sul, quanto à s questões de intervenção humanitária, não se concretizou (IGNATIEFF, 2012).

Esta dissensão e diferença de entendimentos sobre como efetivar a proteção dos civis está conectada com o aspecto mutável dos interesses na análise construtivista, assim como a sua expressão na construção da ação dos Estados (FINNEMORE, 1996a; FINNEMORE,1996b). Na tentativa de conciliar essas diferentes perspectivas surgiu a proposta brasileira da RwP.

\footnotetext{
${ }^{8}$ Segundo Rameh Thakur (2011), a intervenção da OTAN foi um sucesso, e marca o processo de construção da R2P como norma emergente, e aponta que os países que se abstiveram na votação da Resolução n¹973 fizeram uma escolha equivocada ao ficar de fora deste processo.

9 Ver conceito de relutância de acordo com Sandra Destradi em Kenkel e Destradi, 2019, p. 5-6.

${ }^{10}$ Aqui se refere à norma da RwP numa concepção formal e jurídica.
} 


\section{Responsabilidade ao Proteger (RwP)}

A fim de auxiliar na construção de um consenso de significado sobre os fundamentos da norma o Brasil propôs a RwP.Dito de outro modo, “a RwP é uma tentativa de proteger a R2P de alguns genes ruins em seupróprio DNA” (POWERS, LINDBLAD, et al., 2015, p. 9, tradução nossa), ou seja, aprimorar a R2P.

A intervenção na Líbia em 2011 proporcionou uma oportunidade para o reinício das discussões em torno do contraste entre o princípio da não intervenção, a soberania e os DH, oportunidade aproveitada pelo Brasil (SERRA, 2015, p. 99). A Representante Permanente do Brasil junto à ONU enviou uma carta ao Secretário-Geral com uma nota conceitual anexada e intitulada "Responsabilidade ao Proteger: elementos para o desenvolvimento e promoção de um conceito" a fim de explicitar o conceito da RwP mencionada pela presidenta em seu discurso na AGNU.

Durante o período de análise (2011) a ONU, o ambiente institucional do desenvolvimento da norma, foi cenário de uma conjuntura única, na qual o Brasil e todos os países do BRICS estavam presentes no CSNU, fosse entre os P5, como a China e Rússia, ou como membronão permanente, no caso da Índia e África do Sul. O Brasil, nesse período (2010 -2011), era membro não permanente do CSNU o que proporcionou a ele uma oportunidade de realizar um empreendimento de forma a construir consensos entre os membros do conselho, desempenhar a função de agente normalizador ${ }^{11}$, e ainda demarcar a sua campanha de longa data quanto à necessidade de uma reforma do órgão em questão, para torná -lo mais legítimo e representativo na realidade contemporânea (MRE, [2020]).

Inicialmente, a nota sublinha que a defesa da manutenção da paz e da segurança internacionais, assim como a proteção dos civis, preceitos desenvolvidos desde a criação da ONU, transpassam várias fases, a começar da ideia de intervenções humanitárias, fundamentada no direito de ingerência até o surgimento da R2P (PERMANENT REPRESENTATIVE OF BRAZIL TO THE UNITED NATIONS, 2011).

Quanto à R2P, a nota conceitual da RwP reitera a estruturação da R2P, em três pilares e acrescenta três aspectos limitadores para o uso da força pela comunidade internacional, sobre o terceiro pilar - quando se permite a intervenção pela comunidade internacional, inclusive com a utilização de forças militares - presente no documento da Cúpula Mundial de 2005: o material, o temporal e o formal. (PERMANENT REPRESENTATIVE OF BRAZIL TO THE UNITED NATIONS, 2011, p. 2). Na interpretação brasileira sobre os pilares da R2P, defendem -se que estes deveriam seguir um sequenciamento cronológico e uma subordinação política, de forma a respeitar a concepção de que o uso da força deve ser exercido somente como último recurso, após esgotarem-se todas as soluções diplomáticas (PERMANENT REPRESENTATIVE OF BRAZIL TO THE UNITED NATIONS, 2011, p.3). Esta ideia de sequenciamento cronológico não tem como fonte o documento da Cúpula Mundial de 2005, e nem o relatório do ICISS, muito menos a Carta da ONU e, na prática, coloca -se em discordância com o modelo de estruturação em três pilares não sequenciais, apresentados pelo Ban Ki-moon em 2009, no relatório “Implementando a Responsabilidade de Proteger” (BAN KIMOON, 2009).

O respectivo documento também trata da crescente percepção de que a R2P pode ser usada para outros fins, que não a proteção de civis, como, por exemplo, para mudança de regimes conforme denunciado por alguns países no caso da intervenção no território líbio, depois de rememorar em uma referência indireta ao caso do Iraque e da Líbia, as intervenções fracassadas da ONU no final do século XX e suas consequências desastrosas para as populações civis (PERMANENT REPRESENTATIVE OF BRAZIL TO THE UNITED NATIONS, 2011, p. 3). Entretanto, na estruturação do conceito pelo ICISS, e no documento de 2005 não existem obstruções quanto aos efeitos e repercussões das ações tomadas sobre a R2P direcionarem-se ao fim do regime vigente (KOLB, 2012, pp.13-14).

O ponto central do desenvolvimento do conceito da RwP defendido pelo Brasil é que

\footnotetext{
${ }^{11}$ O Brasil se aproveitou desta oportunidade de voz para desempenhar o seu almejado papel de porta-voz do Sul Global (STEFAN, 2016, p. 109). Porém, o fim do mandato no CSNU limitou o seu posicionamento como empreendedor normativo (STUENKEL; TOURINHO, 2014, p. 394).
} 
[...] ao exercer a responsabilidade de proteger [R2P], a comunidade internacional deve mostrar uma grande responsabilidade enquanto protege [RwP]. Ambos conceitos devem evoluir juntos, com base em um conjunto acordado de princípios, parâmetros e procedimentos fundamentais: [...] (PERMANENT REPRESENTATIVE OF BRAZIL TO THE UNITED NATIONS, 2011, pp.3-4, tradução nossa).

Quanto à esse conjunto de princípios, parâmetros e procedimentos, resumem -se os pontos principais: 1) a primazia da prevenção, destacando-se a diplomacia preventiva parareduzir o risco de conflitos armados e custos humanos a eles associados; 2) o esgotamento de todos os meios pacíficos disponíveis para proteção dos civis; 3) o respeito aos princípios e propósitos da Carta da ONU e ao consenso estabelecido em 2005; 4) o uso da força vinculado à autorização do CSNU ou AGNU, em circunstâncias excepcionais, conforme o mecanismo “Unidos pela Paz”, e limitado por elementos legais, operacionais e temporais; 5) o uso da força também não deve gerar cenário mais violento e instável do que aquele que foi autorizado a impedir, assim como o seu exercício deve ser criterioso, limitado e proporcional aos objetivos do mandato; 6) o aprimoramento dos procedimentos do CSNU para monitorar a implementação dos mandatos e responsabilização daqueles autorizados a utilizar a força, de forma a garantir que exerçam a responsabilidade que lhes cabe enquanto buscam proteger as populações; e 7) esses parâmetros devem ser considerados durante toda a vigência da resolução do CSNU (PERMANENT REPRESENTATIVE OF BRAZIL TO THE UNITED NATIONS, 2011, pp. 3 -4).

Realizando uma análise das fontes normativas possíveis destes, em meio ao conjunto normativo da R2P, a proposta tem proveniência implícita nas tradições da teoria da guerra justa, e explicitamente no DI, igualmente a R2P, assim como na Carta da $\mathrm{ONU}^{12}$ e no Estatuto de Roma do Tribunal Penal Internacional (TPI). ${ }^{13}$ Além do mais, em um dos seus tópicos destaca-se que a execução do uso da força deve respeitar o DI, especialmente o DIH e o DICA, o que só reforça a limitação das normas e princípios internacionais a esses arcabouços de regras. Ainda sobre as fontes da RwP apreciadas, acrescentam-se: o relatório R2P do ICISS, o qual não foi literalmente citado na nota conceitual, os relatórios do SecretárioGeral, particularmente o do Painel de Alto Nível sobre Ameaças, Desafios e Mudanças de 2004, e o Documento Final da Cúpula Mundial de 2005 (ICISS, 2001, p. XII; ONU, 2004, pp. 66-67; UN GENERAL ASSEMBLY, 2005, p. 31 e 32). A presente pesquisa procurou comparar e relacionar as fontes normativas de cada princípio, re spectivamente, porém, por falta de espaço, não apresentaremos aqui a comparação detalhada.

\section{Reação internacional à RwP}

O Brasil, por meio da RwP, reafirma o seu comprometimento e aceitação dos princípios da R2P, e busca relembrar princípios já presentes na base normativa da R2P que estabelecem critérios para o uso da força. Consequentemente, verificou-se uma polarização de opiniões sobre a intenção brasileira e a contribuição da RwP, para o debate das intervenções humanitárias (TOURINHO; STUENKEL; BROCKMEIER, 2016).

Em 21 de fevereiro de 2012, a missão brasileira permanente na ONU organizou um debate informal sobre a nota conceitual com a presença do Ministro das Relações Exteriores, Antônio Patriota, e o Assessor Especial da ONU para a R2P, Edward Luck. Nesta reunião, estiveram presentes trinta e sete Estados-membros, algumas ONGs, observadores, e três organizações da sociedade civil: Global Centre for the Responsibility to Protect (GCR2P) ${ }^{14}$, Campaign for Innocent Victims in Conflict $(\text { CIVIC })^{15}$, and Human Rights Watch $(H R W)^{16}$, assim como o Assessor Especial da ONU para a Prevenção do

\footnotetext{
${ }^{12}$ Vale destacar que a reivindicação da RwP por um melhoramento dos processos do CSNU, apesar de imprecisa, pois que não especifica que procedimentos, em particular, precisam ser aperfeiçoados, pode resgatar uma questão importante quanto à aplicação do Artigo 42 , Capítulo VII da Carta da ONU.

${ }^{13}$ O TPI é o primeiro tribunal criminal internacional permanente do mundo, e investiga e julga indivíduos acusados dos mais graves crimes como crimes de genocídio, crimes contra a humanidade, crimes de guerra e crimes de agressão (ICC, [2020]). Sendo alguns destes compreendidos no arcabouço da R2P.

${ }^{14}$ Global Centre for the Responsibility to Protect (GCR2P) foi criado em 2008, com o intuito de defender a R2P e mobilizar a comunidade internacional para ações em prol da proteção das populações de crimes de atrocidade em massa. (GLOBAL CENTRE FOR THE RESPONSIBILITY TO PROTECT, [2020]).

${ }^{15}$ Campaign for Innocent Victims in Conflict (CIVIC) é uma organização fundada em 2003 por Marla Ruzicka, que representa a voz dos civis envolvidos em conflitos em todo o mundo, buscando formas de prevenir e responder os danos aos civis. (CENTER FOR CIVILIANS IN CONFLICT, [2020]).

${ }^{16}$ Human Rights Watch (HRW) investiga e relata abusos dos DH ocorridos em todos os cantos do mundo. (HUMAN RIGHTS WATCH, [2020]).
} 
Genocídio, Francis Deng (ICRtoP, 2012, p. 1). Nessa reunião é possível ter uma percepção geral da opinião dos países membros da ONU quanto à ideia da RwP proposta pelo Brasil. Analisamos as declarações de doze países (Estados Unidos, Alemanha, Dinamarca, Gana,Austrália, Costa Rica, Portugal, Guatemala, África do Sul, Quênia, Venezuela e Holanda), e da União Europeia. A seleção dos depoimentos se utilizou do critério de pertinência para a análise em questão, e a disponibilidade dos argumentos.

A maioria das declarações dos representantes dos Estados reforça a consolidação do consenso instituído sobre a estrutura do R2P durante a Cúpula Mundial de 2005, comobase para as discussões, demarcando que o debate sobre a RwP não veio buscar uma renegociação da R2P, mas sim desenvolver a implementação da norma (ICRtoP, 2012, p. 2). Como, por exemplo, o depoimento de Portugal o qual expôs a sua opinião ao afirmar que “[...] a prop osta brasileira não muda, ou pretende mudar o conceito de R2P sobre o qual o consenso deve ser preservado” (PORTUGAL, 2012, p.1, traduçãonossa).

Após a exposição dos depoimentos e opiniões, e/ou visões de determinados países sobre a RwP, podemos sumarizar que o papel primordial da prevenção foi um aspecto de consonância entre os Estados. Já o sequenciamento cronológico dos três pilares e dos respectivos diferentes meios de reação internacional do terceiro pilar foi repelido pela maioria dos Estados-membros, na crença de que ambos os pilares apresentam semelhante relevância, com exceção da Índia e da Malásia, que se colocaram a favor (ICRtoP, 2012, p.3).

Na consideração da RwP, de forma geral, alguns Estados examinaram a nota conceitual somente como um conjunto de orientações para implementação da R2P, enquanto outros apreciaram a potencialidade construtiva do conceito sobre a R2P. Entretanto, a perspectiva predominante era a ideia de complementação entre as concepções, com ressalva para a visão do Quênia, que se referiu às duas noções como conceitos de mesmo nível (KOLB, 2012, p. 19). Guatemala, por exemplo, defendeu que a RwP buscou “[...] explorar com mais detalhes exatamente os aspectos que geram mais controvérsia. Essa é outra maneira de dizer que o Brasil está fornecendo ideias construtivas para um debate que continua a ser indispensável, [...]” (GUATEMALA, 2012, p.2, tradução nossa).

Sob a análise dos depoimentos dos Estados-membros, percebeu-se a desconfiança, especialmente dos países do Norte Global, com a RwP, representada pela noção de concorrência ou competição entre a R2P e a RwP (SERRA, 2015, p. 56). Não obstante, nota-se um entendimento compartilhado de que a proposta da RwP serviu como reativadora do debate sobre formas de implementação da R2P, mesmo por parte dos países mais indagadores, e que no futuro deveria ser organizado um debate sobre a R2P na sua totalidade, e as ações possíveis sob o terceiro pilar (SERRA, 2015, p. 56; ICRtoP, 2012).

Percebe-se que tanto países do Norte quanto do Sul Global questionaram a RwP, e inicialmente os primeiros o percebiam muito restritivo, enquanto os últimos, especialmente outros integrantes do BRICS, como a Rússia, flexível demais (STEFAN, 2016, p. 106; BENNER, 2013,p. 44; STUENKEL, 2012).

[...] em inícios de 2012, o Ocidente não estava ainda preparado para tal [um país do Sul Global propondo debate sobre uma norma], o Brasil se viu rejeitado de praticamente todos os lados. Não apenas o Ocidente em grande medida reagiu negativamente. [...]. Mas também a China e a Rússia mostraram-se céticas, porque a RWP brasileira continha um endosso da necessidade de intervir em casos graves. Enquanto isso, outras potências emergentes, como a Índia e a África do Sul, não tinham muito a dizer sobre a iniciativa RWP. (BENNER, 2013, p. 44).

De modo geral, a polarização de críticas sobre a RwP estava entre os que acreditavam que a RwP era um avanço para a R2P, ao harmonizá-la com as preocupações do Sul Global, e os que defendiam que era uma forma de dificultar a efetivação da implementação da R2P (KENKEL; ROSA, 2015, pp. 20 e 21). Não obstante, com o passar do tempo, alguns países ocidentais consideraram a capacidade da RwP de contribuir, para se evitar a oposição entre o "Ocidente e os que propõem um conceito absolutista de soberania, como a Rússia e a China” (BENNER, 2013, p. 39); ou seja, entre o Norte e o Sul Global, principalmente em torno do terceiro pilar da R2P (QUINTON-BROWN, 2013, p. 63; KENKEL; STEFAN, 2016 , p. 51). Segundo o representante de Gana na ONU, 
se a R2P reconfortar nossas populações de proteção onde quer que estejam, o RWP deve incentivar nossos povos e seus respectivos governos a permanecer comprometidos com a R2P. [...] Portanto, incentivamos o apoio a essa iniciativa oportuna, que só pode servir para fortalecer o conceito de R2P, garantir uma implementação eficaz e promover a propriedade global do processo. (GANA, 2012, p. 2, tradução nossa).

Em outros termos, a RwP seria uma forma de agregar as diferentes visões dos países desenvolvidos e em desenvolvimento, sobre as questões de intervenção (KENKEL; ROSA, 2015, p. 20). De tal maneira, houve a alusão do conceito da RwP em uma seção do relatório do Secretário-Geral da ONU sobre a R2P, denominado "Responsabilidade de proteger: resposta oportuna e decisiva”, emitido em 25 de julho de 2012 (BAN KI-MOON, 2012, p. 13). Sendo, a RwP, por sua vez, um exemplo de como o debate sobre as intervenções humanitárias se converteu em um lócus identificado pelas potências emergentes para dar conteúdo normativo a sua relutância à ordem assente (KENKEL; MARTINS, 2016, p. 23).

\section{Análise da iniciativa normativa do Brasil (RwP)}

Interessados em alcançar o objetivo da pesquisa, isto é, descobrir o modo de inserção da RwP no quadro das normas de intervenção humanitária, analisa-se em seguida as seguintes perspectivas: complementação, inovação e contestação. O objetivo do Brasil com a RwP, conforme discurso dos representantes do país, foi complementar, e ajudou no crescimento conjunto da R2P e RwP, e não se caracterizou como um ataque ou competição ao consenso internacional estabelecido em 2005 na Cúpula Mundial. Elucidando assim a coerência e compatibilidade da RwP com a R2P. A RwP se caracteriza como uma proposta normativa sobre uma outra regra existente, a R2P, de modo a acrescentar critérios e reforçar a sua aplicação apresentada por um país do Sul Global.

Na votação da Resolução n¹973, apesar de não terem se verificado votos contrários, num primeiro momento, a interpretação da abstenção do Brasil poderia expressar uma possível reprovação à R2P, principalmente quanto ao seu terceiro pilar. Entretanto, após analisar a justificativa dada pelo Brasil no momento da votação, e a RwP detalhadamente, verifica-se que a visão do país, quanto à implementação da R2P, era interpretada de forma divergente da maioria do CSNU, ou ainda, quanto aos redatores da resolução (ONU, 2011, p. 6; ADAMS, 2012, p. 2). ${ }^{17}$

O Brasil estava preocupado com a letra do mandato, isto é, achava que o uso da força não era a melhor resposta às atrocidades cometidas por Gadaffi (ONU, 2011, p. 6), o que não quer dizer que este reprovava a R2P, mas que já considerava o princípio do uso da força como último recurso. Ele ainda destacou que esta medida, no caso da Líbia, poderia causar mais danos aos civis ao invés de protegê-los, o que remonta ao princípio do equilíbrio das consequências (ONU, 2011, p. 6). Portanto, a interpretação do Brasil quanto à implementação da R2P realizada já no caso da Líbia, anterior à proposta normativa, é diferente do consenso comum entre a maioria dos Estados-membros, e já incluía os princípios que foram detalhados na RwP, o que nos faz constatar que a RwP reflete a compreensão deste país sobre as diretrizes práticas da norma.

Além de refletir o seu entendimento, ele também possivelmente espelha a percepção de outros países, uma vez que estes apoiam a ideia, mas também retrata princípios de política externa do Brasil como diplomacia e diálogo, ao defender que estas seriam as melhores formas de garantir a proteção da população da Líbia. Sendo assim, países que concordaram, de certa forma, com os aspectos da RwP, destacados pelo Brasil, também compartilham entendimentos semelhantes sobre estes princípios, e, por isto, demarcaram um apoio à ideia (KOLB, 2012, pp. 19 -20; SERRA, 2015, p. 56). Seriam eles, segundo a nossa análise, o Quênia, a África do Sul e a Venezuela.

Quanto à questão colocada sobre o aspecto inovador da RwP, a maior parte da literatura afirma que não houve inovação. A partir da análise dos princípios da RwP, detalha damente e em confrontação com o acervo da R2P, realmente

\footnotetext{
${ }^{17}$ Relembrando que os redatores da resolução foram: Estados Unidos, Reino Unido, França e Líbano (GONÇALVES; SOCHACZEWSKI, 2015, p. 777).
} 
não se verificam inovações conceituais nos critérios expostos, em vista de que todos retomam princípios já presentes no grande quadro de regras das intervenções humanitárias, mas o esforço em esquema tizar estes de forma concisa, e realizar uma reunião exclusiva para discuti-los pode ser considerado um empreendimento inovador incremental. ${ }^{18}$

Nunca antes perguntas sobre quem deveria intervir, sob que autoridade legítima e com quais mecanismos de transparência e responsabilidade foram debatidas de maneira tão explícita em um ambiente com um público tão amplo e com esse nível de detalhe (STUENKEL;TOURINHO, 2014, p. 394, tradução nossa).

Vale destacar que o princípio da RwP não foi incorporado ou infundido ao quadro normativo global formalmente, e nem teve expressão no discurso e nem no comportamento prático dos atores alvos da norma. A RwP é abstrata e não apresenta evidências físicas, com exceção de uma nota conceitual e algumas menções em discursos e relatórios sem caráter vinculativo.

Segundo a definição de contestação da Wiener (2004), como "o leque de práticas sociais, que expressam discursivamente a reprovação de normas” (WIENER, 2014, p. 1, traduçãonossa), e sob a a preciação do discurso e da nota conceitual do Brasil na ONU, a RwP é um exemplo de contestação à norma existente da R2P. Porém, conforme estabelecido por Deitelhoff e Zimmermann (2018), existem dois tipos de contestação: de validade ${ }^{19}$ e da aplicação ${ }^{20}$, e questiona-se em qual destes tipos a RwP se insere.

A partir da análise das fontes normativas das diretrizes da RwP foi possível perceber que, de modo geral, estas já existiam no histórico normativo da construção da R2P, apesar de não constar expressamente no documento de 2005 que representa a consolidação do consenso internacional sobre as intervenções para proteção de civis em casos extremos (PERMANENT REPRESENTATIVE OF BRAZIL TO THE UNITED NATIONS, 2011). Desta forma, constata -se que a proposta do Brasil não acrescentou, e nem rejeitou o valor normativo quanto ao conteúdo da norma em si, o que não a caracteriza como uma contestação de validade. ${ }^{21}$ Além do mais, o Brasil aceitou a R2P integralmente, com base no documento de 2005 (PERMANENT REPRESENTATIVE OF BRAZIL TO THE UNITED NATIONS, 2011). Porém, por retomar alguns princípios e critérios não especificados na consolidação, e que são usualmente apreciados durante a implementação da norma, ou seja, no momento da execução do mandato autorizado pelo CSNU, configura-se como uma contestação aplicacional.

A contestação da aplicação envolve o comportamento exigido das pessoas às quais se aplica a norma em uma situação específica, como direcionado pelos critérios elencados na RwP quanto ao comportamento em campo nas operações sob a R2P, ou ainda à adequação da aplicação de uma norma em uma situação especial, conforme enfatizado na análise de caso a caso. Ademais, dependendo das circunstâncias particulares, esta contestação envolve uma nova compreensão da aplicação da norma, e do comportamento apropriado exigido aos destinatários (DEITELHOFF; ZIMMERMANN, 2018, p.2).

Resumindo, "o RwP foi, com efeito, uma forma de reconceitualização da norma RtoP e um apeloà mais debate $\mathrm{e}$ deliberação sobre, não apenas o que era RtoP, mas como implementá-lo efetivamente para realmente salvar vidas "(POWERS, LINDBLAD, et al., 2015, p. 5, traduçãonossa).

\footnotetext{
${ }^{18}$ Utilizamos aqui a concepção de inovação incremental, com base no conceito empregado no âmbito econômico quanto as relações entre Ciência, Tecnologia e Inovação, no qual a inovação pode ser tanto radical quanto incremental (ABERNATHY; UTTERBACK, 1978). "A inovação incremental é compreendida como a exploração de formas existentes ou tecnológicas, podendo tanto melhorar qualquer coisa que já existe ou re-configurar uma forma ou tecnologia existente para servir a outros propósitos” (DAY; SCHOEMAKER; GUNTHER, 2003). Numa analogia com a RwP, pode-se constatar que esta significou uma inovação incremental.

${ }^{19}$ Segundo as autoras, questionamentos sobre o núcleo das normas, isto é, as alegações básicas da norma, de sua essência, o pilar da sua obrigação normativa, ou melhor, as expectativas normativas compartilhadas caracterizam a contestação sobre a validade (DEITELHOFF; ZIMMERMANN, 2018, p.2).

${ }^{20}$ Quanto aos discursos de contestação da aplicação da norma, esses abrangem a compatibilidade da norma à situação em questão, por meio de uma avaliação do nível de congruência entre a norma e as particularidades do momento. O ponto central engloba interrogações sobre as ações requeridas pela norma na circunstância especial, e como será feita a seleção da norma que será aplicada em determinado contexto quando várias normas puderem ser empregadas (DEITELHOFF; ZIMMERMANN, 2018, p. 7).

${ }^{21}$ De acordo com Kenkel e Destradi, as potências ocidentais continuam a interpretar a relutância das potências emergentes como contestação à validade da norma. (KENKEL; DESTRADI, 2019, p. 7).
} 
Ao retomar alguns princípios e critérios não especificados na consolidação, a RwP ampliou o debate, principalmente, em situações que exigem ouso da força, e discutir sobre eles contribui para a eficiência de sua utilização na prática. Até porque existem diferentes entendimentos sobre os significados de cada princípio, e incitar o seu debate e apresentar a sua visão sobre ele, como fez o Brasil, por meio da criação dessa nota conceitual, foi uma forma de provocar uma faísca quanto à procura de uma consonância dentre os seus diferentes entendimentos e significados em uso. Porém, essa faísca encontrou anteparo e não conseguiu vingar. O Brasil não consolidou o debate sobre a RwP e nem o consenso sobre os significados de seus princípios ou a sua implementação, fazendo-nos questionar as razões desta ausência de seguimento cristalizando o seu caráter propositivo.

O Brasil não mencionou mais o conceito da RwP nas sessões de abertura da AGNU depois de 2012, na sexagésima sétima sessão, apesar de ter sido acrescentado em alguns debates e documentos ${ }^{22}$, e o ministro Patriota ainda mencionálo em seus discursos e artigos em 2013. ${ }^{23}$ A temática das intervenções humanitárias e, especificamente, o uso da força, não deixaram de ser prioridade, ou de ter importância para o país, porém a promoção e propaganda do conceito não estavam mais na agenda do governo (WELSH, QUINTON-BROWN; MACDIARMID, 2013, p. 8; TOURINHO; STUENKEL; BROCKMEIER, 2016, p.143).

No discurso da abertura da $67^{\text {a }}$ Sessão da AGNU, em setembro de 2013, o Brasil não aproveitou a oportunidade para aprofundar esta iniciativa, configurando uma postura tímida, já que "não se lançou à qualquer esforço diplomático para ampliar a coalisão RwP” (BENNER, 2013, p. 43; STUENKEL, 2013, p. 61; STUENKEL; TOURINHO, 2014, p. 394). Deste modo, a presente pesquisa buscou, também, identificar que fatores explicam a falta de esforço do Brasil em consolidar o conceito da RwP. Elencamos e exploramos cinco possíveis razões para a ausência da implementação da RwP, e conseguinte evolução da norma: as alterações do contexto doméstico e institucional; a presença, e/ou retirada do empreendedor normativo representado pelo Patriota; o alto custo diplomático do empreendimento; e a falta de articulação de apoio com outros atores no ambiente normativo.

Após análise constatou-se que as razões elencadas esclarecem a não consolidação do conceito da RwP, e paralelamente, a falta de implementação. Vale ressaltar que os três primeiros motivos, além de explicar o desmantelamento da promoção do conceito, também se apresentam como fatores viabilizadores da iniciativa empreendedora do Brasil. Porém, essencialmente, destacou-se a falta de articulação do conceito com outros países com visões similares no ambiente normativo como motivo principal. Sendo assim, a RwP é uma iniciativa normativa empreendedora do Sul Global devido à posição de seu criador, e não de uma coordenação e um consenso dos países da periferia mundial e, como resultado, não evoluiu no quadro normativo.

\section{Considerações Finais}

A presente pesquisa considerou um fragmento do grande panorama de evolução das normas de intervenção humanitária de forma geral, ou seja, das regras que envolvem o emprego da força no intuito de apresentar onde e como normas novas, ou melhor, modificadas pelos países da periferia mundial, particularmente a RwP, se inserem no meio normativo internacional. Desta maneira, após relatar a mudança verificada nos entendimentos sobre o objetivo do uso da força e no contexto normativo internacional, sob uma visão sistêmica, contextualizamos o surgimento da R2P, norma que a RwP buscou contestar.

\footnotetext{
${ }^{22}$ Como por exemplo, na III Cúpula América do Sul-Países Árabes (ASPA) ${ }^{22}$ em Lima, onde foi elaborada a Declaração de Lima que reforça os princípios da RwP e afirma apoio total ao conceito (MRE, 2012); e na VII Reunião Ministerial da Zona de Paz e Cooperação do Atlântico Sul (ZOPACAS), no Uruguai, onde foi estabelecida a Declaração de Montevidéu, na qual os países concordam em reconhecer a contribuição útil do Brasil atr avés do conceito.

${ }^{23}$ Antônio Patriota, em 2013, se esforçou na divulgação da RwP ao mencionar a sua importância em seus discursos e artigos, como por exemplo, no Debate Aberto do CSNU sobre Proteção de Civis em Conflitos Armados, em Nova York; na 22a Sessão do UNHRC, em Genebr a; no seminário sobre o papel do Brasil nas estruturas de governança global no Peace Research Institute Oslo (PRIO). (PATRIOTA, 2016, pp.117-121 e 177).
} 
No contexto de ausência de um consenso sobre o uso da força para proteção de civis em casos extremos identificou-se uma situação de conflito de significados que a R2P procurou resolver, porém, após a sua aplicação na intervenção militar na Líbia, representada pela Resolução n¹973, que teve cinco abstenções de voto, verificou -se a persistência da divergência de interpretações sobre os princípios -base da norma.

A partir da perspectiva de que todas as pessoas possuem uma bagagem normativa específica (WIENER, 2007b,p. 14), acreditamos que as interpretações sobre o significado dos critérios da R2P e RwP alteram -se segundo o contexto de cada país, assim como o seu local na hierarquia internacional. Sendo assim, o entusias mo do Brasil com esta proposta não deriva somente de fatores externos, do mesmo modo que também nãoé determinada apenas por reivindicações internas, mas é consequência de mudanças no quadro normativo em geral somado ao contexto regional, doméstico e institucional.

A RwP foi abordada como exemplo de uma tentativa normativa imersa no escopo internacional das regras sobre o uso da força, mas ressaltando o seu caráter propositivo, decorrente da falta de disposição do Brasil em consolidar o conceito no âmbito da ONU. Tendovista que o posicionamento ativo e construtivo do Brasil ao se dispor a contribuir com o debate da R2P e torná-lo mais refinado e produtivo, foi limitado por alguns fatores domésticos, institucionais e operacionais.

Conforme discurso dos principais representantes do país na ONU, o objetivo do Brasil foi complementar e ajudar no crescimento conjunto da R2P e RwP, e não se caracterizou como um ataque ou competiçãoà consonância internacional sobre a temática. A nota conceitual procurou clarificar o significado, istoé, o entendimento de uma norma universal criada por países ocidentais, de modo a contribuir com o seu desenvolvimento e incluir a sua perspectiva, ou melhor, a interpretação dos países do Sul Global.

Após a análise comparativa dos princípios colocados pela RwP, e as fontes normativas da R2P, identificamos que a iniciativa brasileira não foi inovativa referente ao conteúdo. Não obstante o esforço em esquematizar estes de forma concisa, e realizar uma reunião exclusiva para discuti-los pode ser considerado um incremento.

Utilizando a tipificação de contestação de Deitelhoff e Zimmermann, constata -se que a proposta do Brasil não foi contestação de validade, pois não se refere à base conceitual da norma, mas ao operacional desta. Além do mais, o Brasil aceitou a R2P integralmente, com base no documento de 2005. Porém, por retomar alguns princípios e critérios não especificados na consolidação, e que são usualmente apreciados durante a implementação da norma, a RwP representa uma contestação aplicacional.

Sob uma visão sistêmica, a RwP é a expressão da relutância de países da periferia mundial em relação à dominância ocidental sobre as definições e implementação do uso da força no cenário internacional. Especificamente, da desigualdade de poder de decisão no CSNU. Deste modo, a RwP é exemplode uma forma de agência de países periféricos na dinâmica normativa.

O histórico da participação brasileira em operações de paz da ONU, e sua correlação com a política externa, evidencia que o nível de engajamento e relevância da presença brasileira nas missões de paz atingiu um patamar capaz de causar um impacto na dinâmica global de intervenções humanitárias. Com o intuito de complementar este efeito e reforçar sua posição de ator global, a RwP foi elaborada pelo Brasil na oportunidade em que este percebeu uma brecha para o questionamento dos reflexos da estrutura hierárquica do CSNU.

Enfim, a RwP foi uma forma de contribuição complementar à atuação humanitária, por adicionar valor à dimensão prática quanto à aplicação da norma legitimadora das intervenções, de maneira menos onerosa, isto é, sem os grandes gastos militares expendidos nas operações de paz. Portanto, podemos caracterizar a RwP como uma iniciativa normativa contestativa aplicacional do Sul Global complementar à atuação humanitária.

Reconhecemos que a presente análise não esgota o debate acerca da etapa contestativa das normas de intervenção humanitária, mas acreditamos que o corrente trabalho ajudou a elucidar, que ainda existem conflitos e divergências de entendimentos normativos, novasto quadro das intervenções humanitárias, principalmente, sob a perspectiva de um país 
do Sul Global. Desejamos que a elucidação destes desentendimentos possibilite um avanço nas tentativas de proteção das populações de casos de violência extrema.

\section{Referências}

ABERNATHY, W.; UTTERBACK, J. Patterns of industrial innovation. Technology Review, v. 80, n. 7, June/July 1978.

ACHARYA, A. How Ideas Spread: Whose Norms Matter? Norm Localization and Institutional Change in Asian Regionalism. International Organization, v. 58, n. 2, p. 239-275, Spring 2004.

ACHARYA, A. The Responsibility to Protect and a theory of norm circulation. In: THAKUR, R.; MALEY, W. Theorising the Responsibility to Protect. Cambridge: Cambridge University Press, 2015. p. 59-78.

ADAMS, S. Emergent Powers: India, Brazil, South Africa and the Responsibility to Protect. The World Post, 2012. Disponível em: <https://www.huffingtonpost.com/simon-adams/un-india-brazil-south-africa_b_1896975.html>. Acesso em:06 Novembro 2017.

ANNAN, K. We the peoples: the role of the United Nations in the twenty-first century. Report of the Secretary-General. UN. New York. 2000.(A/54/2000).

BAN KI-MOON. Responsible Sovereignty: International Cooperation for a Changed World, Berlin, 2008. Disponível em: <http://www.un.org/press/en/2008/sgsm11701.doc.htm>. Acesso em: 7 Dezembro 2016.

BAN KI-MOON. Implementing the responsibility to protect: Report of the Secretary-General. UN. New York. 2009. (A/63/677).

BAN KI-MOON. Responsibility to protect: timely and decisive response. Report of the Secretary-General. UN. New York. 2012. (A/66/874-S/2012/578).

BELLAMY, A. J.; WILliAMS, P. D. The New Politics of Protection? Côte d'Ivoire, Libya and the responsibility to protect. International Affairs, v. 4, n. 87, p. 825-850, 2011.

BENNER, T. O Brasil como um empreendedor normativo: a Responsabilidade ao Proteger. Política Externa,v.21, n. 4,Abr/Mai/Jun 2013.

BIERRENBACH, A. M. O conceito de Responsabilidade de Proteger e o Direito Internacional Humanitário. Brasília: Fundação Alexandre de Gusmão, 2011.

BIGATÃO,J.D.P. Manutenção da Paz e Resolução de Conflitos: Respostas das Nações Unidas aos Conflitos Armados Intra-estatais na década de 1990. Programa de Pós-Graduação em Relações Internacionais San Tiago Dantas (UNESP/UNICAMP/PUC-SP). São Paulo. 2009.

BRAZIL. Statement by H.E. Dilma Rousseff, President of the Federative Republic of Brazil, at the Opening of the General Debate of the 66th Session of the United Nations General Assembly, New York, 21 September 2011. Disponível em: <http://gadebate.un.org/sites/default/files/gastatements/66/BR_en_0.pdf>. Acesso em: 05 janeiro 2020.

CARPIO, D. F. S. V. D. A responsabilidade de proteger e o conselho de segurança das nações unidas: uma análise dos argumentos apresentados no caso da intervenção humanitária na Líbia e o reflexo no caso sírio no período 2011 -2012. Universidade Federal de Santa Catarina. Florianópolis, p. 169.2014.

CENTER FOR CIVILIANS IN CONFLICT. About us, [2020]. Disponível em: <https://civiliansinconflict.org/about-us/>. Acesso em: 20 mai. 2020.

DAY, G. S.; SCHOEMAKER, P.; GUNTHER, R. Gestão de Tecnologias Emergentes: A visão de Wharton School. [S.1.]: Bookman, 2003.

DEITELHOFF, N.; ZIMMERMANN, L. Things we lost in the fire: How different types of contestation affect the robustness of international norms. International Studies Review, 2018.1-26.

Digolin, K. A. Cooperação em Operações de Paz: Atuações e Iniciativas Conjuntas entre Argentina, Brasil e Chile. Programa de Pós-graduação em Relações Internacionais San Tiago Dantas. São Paulo. 2018.

EVANS, G. The Responsability to protect: an idea whose time has come and gone? International Relations, v. 22, n. 3, p. 283-298,2008.

FINNEMORE, M. Constructing Norms of Humanitarian Intervention. In: KATZENSTEIN, P. The Culture of National Security. New York: Columbia University Press, 1996a.

FINNEMORE, M. National interests in international society. Ithaca and London: Cornell University Press, $1996 \mathrm{~b}$.

FINNEMORE, M. The purpose of intervention: changing beliefs about the use of force. Ithaca and London: Cornell University Press, 2003.

FINNEMORE, M.; SIKKINK, K. International Norm Dynamics and Political Change. International Organization, v. 52, n. 4, p. 887-917, 1998 
FLORINI, A. The Evolution of International norms. In: International Studies Quarterly, v. 40, n. 3, p. 363-389, September1996.

GANA. Statement by the Permanent Representative of Ghana, William Awinador-Kanyirige at the Informal Discussion on the "Responsibility while Protecting” Initiative. [S.1.]. 2012.

GLOBAL CENTRE FOR THE RESPONSIBILITY TO PROTECT. About us, [2020]. Disponível em: <https://www.globalr2p.org/about/>. Acesso em: 20 mai. 2020.

GONÇALVES, A. C.; SOCHACZEWSKI, M. Intervenção na Líbia e "Primavera Árabe": Interpretações Possíveis. Coleção Meira Mattos, Rio de Janeiro, v. 9, n. 36, p. 769-780, Setembro/Dezembro 2015.

GUATEMALA. Remarks of Gert Rosenthal, permanent representative of Guatemala to the United Nations at the informal discussion on "the responsibility while protecting" organized by the permanent mission of Brazil to the United Nations. [S.l.]. 2012.

HUMAN RIGHTS WATCH. About us, [2020]. Disponível em:<https://www.hrw.org/about/about-us>. Acesso em: 20 mai. 2020.

ICC.About. International Criminal Court, [2020]. Disponível em:<https://www.icc-cpi.int/about>. Acesso em:14 fevereiro 2020.

ICISS. The Responsibility to Protect: report of the International Commission on Intervention and State Sovereignty. International Development Research. Ottawa: [s.n.]. 2001.

ICRTOP. International Coalition for the Responsibility to Protect. United Nations Informal Discussion on “Responsibility While Protecting" $21 \quad$ February 2012, 2012. <http://www.responsibilitytoprotect.org/index.php/component/content/article/35-r2pcs-topics/4002-informal-discussion-onbrazils-concept-of-responsibility-while-protecting $>$. Acesso em: 23 janeiro 2020.

IGNATIEFF, M. How Syria divided the world. NYR Daily, 11 July 2012 Disponível em: <http://www.nybooks.com/daily/2012/07/11/syria - proxy-war-russia- china/?printpage=true >.

KELLY, M. Lutando pela vida dos outros: R2P, RWP e a utilidade da força para proteger civis. A implementação da Responsabilidade de Proteger: Novos Rumos para a Paz e Segurança Internacional, Brasília, Março 2013.

KENKEL, K. M.; MARTINS, M. T. Emerging Powers and the Notion of International Responsibility: moral duty or shifting goalpost? Brazilian Political Science Review, v. 10, n. 1, 2016.

KENKEL, K. M.; ROSA, F. D. Localization and Subsidiarity in Brazil's Engagement with the Responsibility to Protect. Global Responsibility to Protect, v. 7, n. 3/4, p. 325-349, 2015.

KENKEL, K. M.; STEFAN, C. G. Brazil and the Responsibility While Protecting Initiative: Norms and the Timing of Diplomatic Support. Global Governance, v. 22, p. 41-58, 2016.

KENKEL, K.; DESTRADI, S. Explaining emerging powers' reluctance to adopt intervention norms: normative contestation and hierarchies of responsibility. Revista Brasileira de Política Internacional, v. 62, n. 1, 2019.

KOLB, A. S. The Responsibility to Protect (R2P) and the Responsibility while Protecting (RWP): Friends or Foes? Global Governance Institute, Belgium, September 2012.

MRE. O Brasil e o Conselho de Segurança da ONU, [2020]. Disponível em: <http://www.itamaraty.gov.br/pt-BR/politica-externa/paze-seguranca-internacionais/137-o-brasil-e-o-conselho-de-seguranca-das-nacoes-unidas >.Acesso em: 2 janeiro 2019.

MRE. Statement of Brazil at the 12th Open Debate of the Security Council on Protection of Civilians in Armed Conflicts, New York, 09 2011. Disponível em: <http://cpdoc.fgv.br/sites/default/files/2011\%2011\%2009\%20Maria\%20Luiza\%20Viotti\%20CSNU\%20\%20Debate\%20Aberto\%20sob re\%20Prote\%C3\%A7\%C3\%A3o\%20de\%20Civis\%20em\%20Conflito\%20Armado.pdf>.Acesso em: 06 março 2020.

MRE. III Cúpula América do Sul-Países Árabes - Declaração de Lima, Lima, 03 Outubro 2012. Disponível em: <http://www.itamaraty.gov.br/pt-BR/notas-a-imprensa/3164-iii-cupula-america-do-sul-paises-arabes-declaracao-de-lima.>. Acesso em: 15 maio 2020 .

ONU. S/PV.6498. Security Council. New York: Official Records of the Security Council. 2011.

ONU. A more secure world: Our shared responsibility. Report of the Secretary-General's High-level Panel on Threats, Challenges and Change. [S.1.]: [s.n.]. 2004

PATRIOTA, A. D. A. Política externa brasileira: discursos, artigos e entrevistas (janeiro a agosto de 2013). Brasília: FUNAG, v. 2, 2016.

PERMANENT REPRESENTATIVE OF BRAZIL TO THE UNITED NATIONS. Responsibility while protecting: elements for the development and promotion of a concept, Annex to the letter dated 9 November 2011 from the Permanent Representative of Brazil to the United Nations addressed to the Secretary-General. A/66/551-S/2011/701. New York: Official Records of the Security Council. 2011. p. 24. 
PORTUGAL. Statement by the Permanent Representative of Portugal, H. E. Ambassador José Filipe Moraes Cabral, Informal Discussion on the "Responsibility While Protecting" Initiative. [S.l.]. 2012

POWERS, M. M. et al. Responsibility While Protecting: Implementation and the Future of the Responsibility to Protect. Columbia Global Policy Initiative, april 2015. Disponível em: <https://academiccommons.columbia.edu/doi/10.7916/D8D23F56>. Acesso em: $10 \mathrm{~m}$ aio 2020.

QUINTON-BROWN, P. The Responsibility While Protecting: Linchpin or Trojan Horse? Implementing the Responsibility to Protect: New Directions for International Peace and Security?, Brasília, March 2013.

SERRA, M. C. Responsabilidade ao proteger: inovação do posicionamento brasileiro na Organização das Nações Unidas? Dissertação (Programa de Pós-Graduação em Relações Internacionais) - Universidade Estadual da Paraíba, Centro de Ciências Biológicas e Sociais Aplicadas.Jõao Pessoa, p. 120, 2015.

STEFAN, C. G. On non-Western norm shapers: Brazil and the Responsibility while Protecting. European Journal of International Security, v. 2, p. 88-110,2016.

STUENKEL, O. BRICS and the 'Responsibility While Protecting Concept'. The Hindu, 2012. Disponível em: <https://www.thehindu.com/opinion/op-ed/BRICS-and-the-\%E2\%80\%98Responsibility-while-Protecting\%E2\%80\%99concept/article13072481.ece>. Acesso em: 27 Abril 2020.

STUENKEL, O. Brazil as a norm entrepreneur: the Responsibility While Protecting. Implementing the Responsibility to Protect: New Directions for International Peace and Security?, Brasília, March 2013.

STUENKEL, O.; TOURINHO, M. Regulating intervention: Brazil and the responsibility to protect. Conflict, Security \& Development, v. 14, n. 4, p. 379-402,2014. Disponível em:<http://dx.doi.org/10.1080/14678802.2014.930593>.

THAKUR, R. International Authority and the Responsibility to Protect. European Journal of International Law, v. 23, n. 1, 2012.

TOURINHO, M.; STUENKEL, O.; BROCKMEIER, S. “Responsibility while Protecting”: Reforming R2P Implementation. Global Society, v. 30, n. 1, p. 134-150, 2016. Disponível em: <http://dx.doi.org/10.1080/13600826.2015.1094452>.

UN GENERAL ASSEMBLY. 2005 World Summit Outcome. GAOR. Sixtieth Session. 2005. A/60/L.1.

WELSH, J.; QUINTON-BROWN, P.; MACDIARMID, V. Brazil's 'Responsibility while Protecting' Proposal: A Canadian Perspective. Canadian Centre for the Responsibility to Protect, February 2013. Disponível em: <http://ccr2p.org/publications - $3>$. Acesso em: 23 Fevereiro 2020

WIENER, A. Contested Meanings of Norms: A Research Framework. Comparative European Politics, n. 5, p. 1-17,2007a.

WIENER, A. Making normative meaning accountable in international politics. WZB Discussion Paper, Berlin, v. SP IV 2007-305, 2007b.

WIENER, A. The Dual Quality of Norms and Governance beyond the State: Sociological and Normative Approaches to Interaction. Critical Review of International Social and Political Philosophy, v. 10, n. 1, p. 47-69, March 2007c.

WIENER, A. A Theory of Contestation. Berlin: Springer, 2014.

ZIEGLER, C. Critical perspectives on the Responsibility to Protect: BRICS and beyond. International Relations, p. 1-16, July 2016.

\begin{tabular}{ll}
\hline Funções de colaboração exercidas & \\
\hline Ana Clara Figueira Guimarães: & Conceituação; Metodologia; Curadoria de dados; Administração do projeto; Visualização; Recursos; Obtenção de financiamento; \\
Luís Alexandre Fuccille: & Investigação; Escrita (primeira redação); \\
\hline
\end{tabular}

